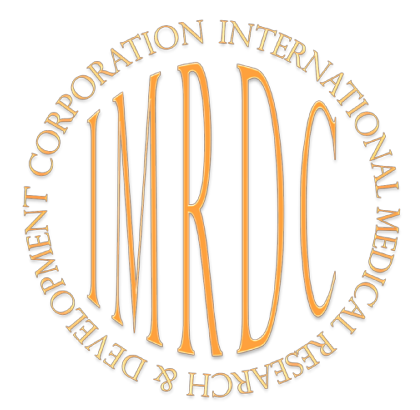

\title{
Reduced Glutamatergic Neurotransmission as Possible Indicator of Unfavorable Prognosis
}

\author{
Elena V. Alekseeva, PhD \\ Central Clinical Hospital of the Presidential Administration of the Russian Federation \\ Moscow, the Russian Federation
}

\begin{abstract}
The paper summarizes the results of experimental and clinical studies showing a reduced function of the glutamatergic neurotransmitter system (GNS) in the development of critical states of the organism. Reduced function of GNS is considered as an unfavorable prognostic factor associated with key mechanisms of thanatogenesis. (Int J Biomed. 2017;7(1):15-23.)
\end{abstract}

Key Words: glutamate $\bullet$ glutamine $\bullet$ kynurenic acid $\bullet$ critically ill patients

\section{Abbreviations}

AAs, amino acid; CNS, central nervous system; CVVH, continuous veno-venous hemofiltration; GNS, glutamatergic neurotransmitter system; GABA, gamma-aminobutyric acid; Glu, glutamate; Gln, glutamine; ICU, intensive care unit; IDO, indoleamine 2,3- dioxygenase; KP, kynurenine pathway; NMDAR, N-methyl-D-aspartate receptor; RGN, reduced glutamatergic neurotransmission; TDO, tryptophan 2,3 dioxygenase.

\section{Introduction}

Modern methods of metabolomics research allow identifying a super-wide range of low molecular weight compounds. This presents a great potential for their use in critical care medicine for understanding the relationships between the factors of microorganisms and the course of the pathological process that is key to improving the disease outcomes. ${ }^{[1]}$ Metabolomics promotes the development of "personalized" medicine based on the application of patientspecific profiles, incorporating genetic and genomic data as well as clinical and environmental factors, to assess individual risks and to improve diagnostics and the target treatment. ${ }^{[2,3]}$

GNS of humans and animals has a wide range of neurogenic and non-neurogenic functions, many of which are still little known. Through GNS components (Glu, Gln, its inactive metabolite and precursor, a wide range of Glu

*Corresponding author: Elena V. Alekseeva, PhD, anesthesiologist-resuscitator of the intensive care unit; the Central Clinical Hospital of the Presidential Administration of the Russian Federation.E-mail: aev69@mail.ru receptors, transporters, and enzymes), transmission of nerve impulses, glutamatergic neurotransmission, is carried out. Glu is an important signaling molecule and a major excitatory neurotransmitter in GNS; its receptors are widely prevalent in phylogenetically very distant species of living organisms. ${ }^{[4]}$ Most, if not all, cells of the central nervous system (CNS) have at least one type of Glu receptor. ${ }^{[5]}$ Under normal physiological conditions, Glu is released as a neurotransmitter into the synaptic cleft and initiates the propagation of action potentials. GNS components have been also identified outside CNS: in heart, liver, kidney, lung, thyroid gland, and skin, in the enteric nervous system, in the "gut-brain axis," in plasma and blood cells ${ }^{[6-9]}$ GNS is involved in the functioning of multiple organ systems: CNS, cardiovascular, respiratory, gastrointestinal, and immune systems, and the hypothalamic-pituitary-thyroid axis. ${ }^{[9-11]}$ Glu-dependent activation of NMDARs in heart allows sufficient influx of calcium to increase myocardial contractility and systolic pressure. ${ }^{[12]}$ Glu induces contraction of ductus arteriosus through GluR-mediated noradrenaline production. Supplementation of glutamate might help to prevent patent ductus arteriosus in extremely preterm infants. ${ }^{[13]}$ Glu also modulates the motor function of the gastrointestinal tract. ${ }^{[14]}$ 
Over the last 4 decades, a number of studies have shown that neurons release more than one neurotransmitter. It has been suggested that monoamine and cholinergic neurons use Glu as a co-transmitter. There is evidence of co-release of Glu and GABA, excitatory and inhibitory fast neurotransmitters, from a single axon terminal in neurons. ${ }^{[15-17]}$ GNS is involved in synaptic and diffuse neurotransmission, the formation of neurons ${ }^{118]}$ and synaptic plasticity. ${ }^{[4]}$ Glu and Gln are multifunctional AAs, which are involved in a large number of metabolic reactions aimed at the detoxification of ammonia, an increase in resistance to hypoxia, and the formation of the antioxidant glutathione, ATP, AAs, and other proteins. ${ }^{[19]}$

Evidence of Glu participation in the regulation of physiological and pathological processes in other organs and tissues (lung, kidney, liver, heart, gastrointestinal tract, and immune system) has been obtained only in recent years. Earlier studies on the GNS role in the development of patients' critical condition were (in the vast majority) experimental or postmortem studies and were focused on the action of Glu in CNS. According to E. Aleksandrova et al., ${ }^{[1]}$ the results of these studies are numerous debated concepts regarding the damaging effect of the increased or decreased extracellular Glu levels on the activity of brain neurons in experimental models of trauma, ischemia, and inflammation.

Glu is not only the primary excitatory neurotransmitter in the adult brain, but also a critical transmitter for signaling neurons to degenerate following stroke. Excitotoxicity, the specific type of neurotoxicity mediated by Glu, is a primary contributor of ischemic neuronal death and other cellular components of the neurovascular unit. Cerebral ischemia leads to a massive release of Glu, which stimulates NMDARs and induces calcium influx through these ionotropic receptors; the calcium-dependent activation of death-signaling proteins that are immediately downstream of the receptors triggers a plethora of signaling cascades that work synergistically to induce neuronal death. ${ }^{[22,23]}$ As scientists begin to understand the critical role of NMDARs and calcium input in excitotoxicity, several strategies have been developed against glutamate excitotoxicity; however, none of them have shown positive results in clinical practice so far, and all NMDAR antagonists failed in clinical trials. ${ }^{[24]}$

In the case of acute processes such as stroke or traumatic brain injuries, glutamate excitotoxicity is thought to cause harm within a narrow timeframe after which the neurotransmitter reassumes its normal function. Therefore, the use of agents acting on NMDAR may have not only missed the window for therapeutic efficacy but also led to undesired side effects from prolonged receptor blockades. ${ }^{[24]}$ Nowadays, the concept of blood/brain glutamate grabbing or scavenging is well recognized as a novel and attractive protective strategy to reduce the excitotoxic effect of excess extracellular glutamate that accumulates in the brain following an ischemic stroke. ${ }^{[25]}$

It is important to note that Glu can produce both adverse (neurotoxic) and positive (anti-ischemic) effects in cerebral ischemia. A study performed by T. Gan'shina et al. ${ }^{[26]}$ found an interaction between excitatory and inhibitory systems on the level of cerebral vessels.

Analysis of the results of a number of experimental and clinical studies allows us to consider reduced glutamatergic neurotransmission (RGN) as a possible indicator of unfavorable prognosis of pathological conditions, as well as a factor associated with the development of key mechanisms of thanatogenesis $^{[27]}$ and main pathological processes with selfdependent thanatological value: systemic hypoxia, sepsis, and acute kidney injury (Figure 1).

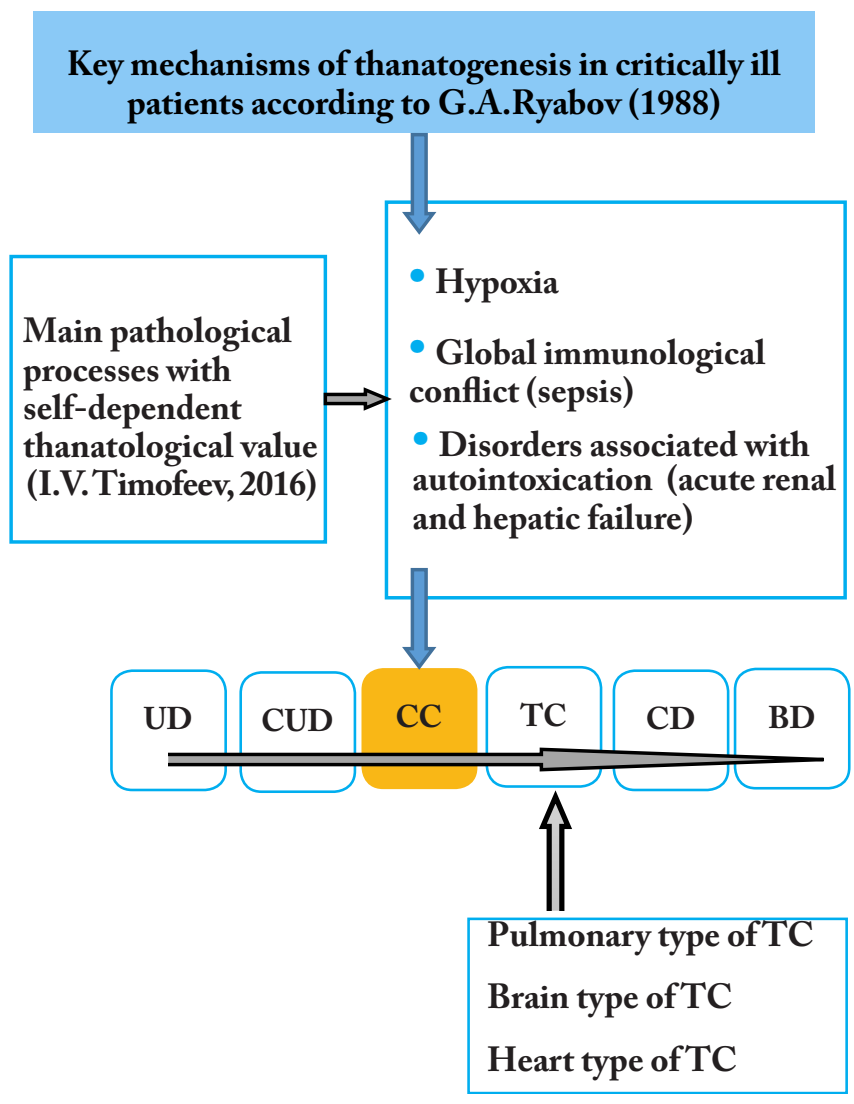

Fig. 1. Key mechanisms of thanatogenesis in critically ill patients according to G.Ryabov (1988) and the schema fragment of pathogenesis and thanatogenesis by I.Timofeev (2016)

$U D$ - underlying disease; CUD- complication of underlying disease; $C C$ - critical condition; TC - terminal condition; $C D$ clinical death; $B D$ - biological death

\section{The neurochemical criteria of GNS hypofunction}

The main neurochemical criteria indicating hypofunction of GNS can be: 1) low level of Glu (or Glu+Gln) in the plasma and investigated tissues in comparison with reference values; 2) an increased level of kynurenic acid (KYNA), a neuroactive metabolite of tryptophan catabolism in enzymatic cascade, known as KP.

Currently, Glu concentrations in cerebrospinal fluid (CSF) and blood plasma are readily available criteria for indirect evaluation of Glu homeostasis in the body. ${ }^{[8]}$ These available biofluids are interpreted as an average representation of the surrounding tissue. ${ }^{[29]}$ The content of mediators and products of their inactivation in plasma and CSF depends on the circulation of neurotransmitters in the tissues and reflects the intensity of neurotransmitter processes. ${ }^{[30]}$ 
Maintaining a relatively constant concentration of extracellular AA pool is one of the functions of the interorgan AA exchange.$^{[31]}$ According to B.Bein and A. Ezhova, ${ }^{[32]}$ the constant maintenance of a certain amount of free AAs in the blood is carried out due to transfer from the gastrointestinal tract and tissue during protein decay, as well as redistribution and consumption of AAs in organs and tissues. The exact mechanisms that lead to a change in the plasma Glu levels remain unknown, but in general, it is release and redistribution of Glu between organs or the activation of neutralizing natural mechanisms. ${ }^{[33]}$ From CNS, neurotransmitters and their metabolic products are released in the blood and CSF. ${ }^{[29]}$ The diffuse and synaptic types of neurotransmission have complex mechanisms of interaction. Researchers have described the movement of Glu from synoptic slit and its participation in the diffuse type of neurotransmission, as well as interactions of "diffuse" Glu with the synaptic (presynaptic and postsynaptic) receptors. ${ }^{[34]}$ For regulation of extracellular concentrations of Glu, its transporters also have a significant effect. Glu transfer by transporters is carried out in both directions of the cell membrane, depending on the gradient of the ions $\mathrm{Na}+/ \mathrm{K}+$ and amino acid itself and may change as a result of metabolic processes. Another major source of extracellular Glu is its release by neurons and glial cells through exocytosis. This process can be triggered by activation of glial glutamate receptors and represents $\mathrm{Ca} 2+$-dependent process. ${ }^{[34]}$

In should be noted that Glu level is closely associated with plasma concentration of KYNA, which is one of the end products of tryptophan formed in KP. KYNA in supraphysiological concentrations (micromolar levels) has an antagonistic effect on all three ionotropic Glu receptors and $\alpha 7 \mathrm{nAChR} .{ }^{[35-37]} \mathrm{An}$ increase in KYNA concentration is accompanied by a decrease in Glu release, and a decrease in extracellular levels of dopamine ${ }^{[38]}$ (Glu via ionotropic receptors indirectly stimulates the dopamine release). ${ }^{[39]}$

The modern methods of metabolomic research are characterized by high manufacturability analysis and, accordingly, the degree and accuracy of determination of low molecular weight substances ${ }^{\left[{ }^{[30]}\right.}$ Among the analytical methods used in metabolomics research, liquid chromatography/ mass spectrometry (LC/MS) has been shown to be one of the best techniques in terms of selectivity, sensitivity, and reproducibility. ${ }^{[40,41]}$ It provides the highest level of metabolite coverage, using a unified analytical technique. In LC-MS, limit of sensitivity is about $5 \mathrm{nM}$ to $10 \mathrm{nM}$ and the number of detectable characteristics - from 5000 to 20000.
In magnetic resonance spectroscopy (MRS), where the detection limit is usually $5 \mu \mathrm{M}$ to $10 \mu \mathrm{M}$, a number of recognizable compounds are from 40 to 200 , depending on the biological material to be analyzed. ${ }^{[42]}$ Measuring the Glu concentration by MRS with the usual values of the magnetic field causes difficulty in distinguishing between Glu and Gln; for this reason, a composite index is often used. ${ }^{[43]}$ Another aspect of modern metabolomic research is the application of multivariate statistical analysis ${ }^{[40]}$ and the construction of predictive models. ${ }^{[30]}$

Thus, the levels of metabolites in the blood plasma reflect the systemic reactions of the body and are considered as a body's response to the disease. ${ }^{[44,45]}$ As will be presented later, with hypofunction of GNS, likelihood of an unfavorable outcome of the pathological process in the following period of time increases, and the development of each thanatogenesis mechanism is associated with a reduced functioning of GNS.

\section{RGN as a risk factor for an unfavorable course of the pathological processes in critically ill patients}

According to M. Poeze et al. ${ }^{[46]}$ and T. Hirose et al..$^{[47]}$, relatively lower values in plasma Glu concentrations may be an independent predictor of poor outcome in patients with sepsis. E.V. Alexandrova ${ }^{[21]}$ found that the syndrome of RGN is prognostically less favorable than glutamatergic redundancy in patients with severe traumatic brain injury.

In our studies, the risk of an adverse outcome in the 28-day period in ICU was significantly higher (5 times) in critically ill patients (with different underlying pathology) with initially reduced plasma Glu levels than in patients with baseline Glu within reference levels. Prognostic significance of positive testing for reduced plasma Glu level in critically ill patients was $82 \%$, and specificity $-84 \% .{ }^{[48,49]}$ The 28 -day survival rates were less in critically ill patients with reduced plasma Glu levels compared to reference values (Gehan's Generalized Wilcoxon test, $\mathrm{P}=0.01544$; Cox's F-test , $\mathrm{P}=0.00163$; Cox-Mantel test , $\mathrm{P}=0.00243$; Peto \& Peto's and Prentice's generalized Wilcoxon, $\mathrm{P}=0.00738$; the logrank test, $\mathrm{P}=0.00507)$. We found direct correlations between reduced plasma Glu levels and the Apache II Score and the SOFA scores for the cardiovascular, hepatic, coagulation, renal and neurological systems (Table 1); and we identified inverse correlations between the reduced plasma Glu levels and hemoglobin oxygen saturation in the superior vena cava ( $\mathrm{ScvO} 2)$.

Table 1.

Correlations between reduced plasma Glu levels and the Apache II Score and the SOFA scores

\begin{tabular}{|c|c|c|c|c|c|c|}
\hline \multirow{4}{*}{$\begin{array}{l}\text { Reduced } \\
\text { plasma Glu } \\
\text { level }\end{array}$} & \multicolumn{6}{|c|}{ Gamma correlations $(\mathrm{P}<0.05)$} \\
\hline & \multirow{2}{*}{$\begin{array}{l}\text { SOFA (total score) } \\
\quad \mathrm{r}=0.564\end{array}$} & \multicolumn{5}{|c|}{ SOFA scores } \\
\hline & & $\begin{array}{c}\text { Cardiovascular system } \\
\mathrm{r}=0.614\end{array}$ & $\begin{array}{c}\mathrm{CNS} \\
\mathrm{r}=0.542\end{array}$ & $\begin{array}{c}\text { Liver } \\
\mathrm{r}=0.569\end{array}$ & $\begin{array}{l}\text { Kidneys } \\
\mathrm{r}=0.583\end{array}$ & $\begin{array}{l}\text { Coagulation } \\
\mathrm{r}=0.362\end{array}$ \\
\hline & $\begin{array}{l}\text { APACHE II score } \\
r=0.400\end{array}$ & $\begin{array}{c}\text { Plasma procalcitonin level } \\
\mathrm{r}=0.368\end{array}$ & $\begin{array}{c}\text { Plasma lactate level } \\
\mathrm{r}=0.373\end{array}$ & & $\begin{array}{c}\mathrm{S}_{\mathrm{cv}} \mathrm{O}_{2} \\
\mathrm{r}=0.621\end{array}$ & \\
\hline
\end{tabular}


The impact of the reduced plasma Glu level on 28day survival rate of critically ill patients was shown in regression models built using the software package Statistica 12 (adequate models: Cox's proportional hazards model, $\mathrm{P}=0.00619$, exponential regression, $\mathrm{P}=0.00323$; lognormal regression, $\mathrm{P}=0.01944$; normal regression, $\mathrm{P}=0.00524$ ) and Predictor Screening on basis of Statistica Data Miner Recipes (Chi-square $=6.946742, \mathrm{P}=0.0084$. $)^{[48 ; 49]}$

Currently, in contrast to previous studies, H. Buter et al. ${ }^{[50]}$ have shown an association between plasma Gln levels and severity of clinical condition calculated on the APACHEIV scale. According to Y. Lin et al., ${ }^{[51} \mathrm{Gln}$ reduces apoptosis of cardiomyocytes and increases their functional activity at low $\mathrm{pH}$. Under experimental conditions, Gln increased the lifespan of rats after asystole.

The prognostic role of the high KYNA content in patients with unfavorable outcome has been confirmed in several clinical trials. In study by W. Dabrowski et al., ${ }^{[52]}$ the concentration of KYNA in the plasma of septic patients with good clinical outcomes decreased gradually over the course of CVVH. In contrast, the concentration of KYNA in the plasma of septic patients with poor clinical results did not decrease over the course of CVVH. In fact, an increase in KYNA concentration was observed. At the same time, the concentrations of CRP, PCT and lactate decreased during CVVH in this group of patients. In the study of G. Ristagno et al., ${ }^{[53]}$ which included 245 patients resuscitated in the first day after cardiac arrest, high KYNA levels were independently associated with ICU death and with 12-month death. L. Darligton et al. ${ }^{[54]}$ showed that KYNA levels were significantly raised in patients with acute stroke who died within 21 days compared with those who survived; KYNA levels were significantly higher at all study time points (the first, second, third, fourth and seventh days after the stroke) in this group of patients.

\section{RGN and hypoxia}

In critically ill patients with signs of systemic hypoxia, reduced levels of plasma Glu concentrations were observed 5 times more often $(\mathrm{P}=0.019478, \mathrm{r}=0.833)$ than in critically ill patients without systemic hypoxia. Direct correlation was found between reduced plasma Glu content and each criterion of systemic hypoxia: an increased level of lactate in the blood plasma $(\mathrm{r}=0.710)$ and reduced $\mathrm{ScvO} 2$ level $(\mathrm{r}=0.621)$. The relationship between the formation of systemic hypoxia and reduced Glu content in the blood plasma was shown in the logistic regression model built using Predictor Screening on basis of Data Miner Recipes Data Miner (Statistica 12). ${ }^{[55]}$

The above data of clinical trials are consistent with the results of experimental work. Changes in the metabolism of Glu and Gln in hypoxic conditions have been presented by several authors as a phenomenon of "metabolic reprogramming". The increased consumption of Glu and/or Gln in hypoxia is shown as a tissue adaptation to anaerobic conditions. Glu has been described as a more "preferred" substrate for fatty acid synthesis than Gln. ${ }^{[56-60]}$ In a pilot study by H. Baran et al., ${ }^{[61}$ an increase in KYNA level had a direct correlation with the severity of hypoxia. KYNA levels in tissues increased by $44 \%$ after $5 \mathrm{~min}$ of asphyxia and $302 \%$ after $20 \mathrm{~min}$ of asphyxia (the critical time limit of survival). According to G. CeresoliBorroni and R. Schwarcz, ${ }^{[63]}$ up to $6 \mathrm{~h}$, asphyxia caused 160 $267 \%$ increases in KYNA levels in neonatal rats. Changes in the metabolism of Glu, Gln and KYNA in the body during hypoxia, which were identified in the experimental and clinical studies, are shown in Figure 2.

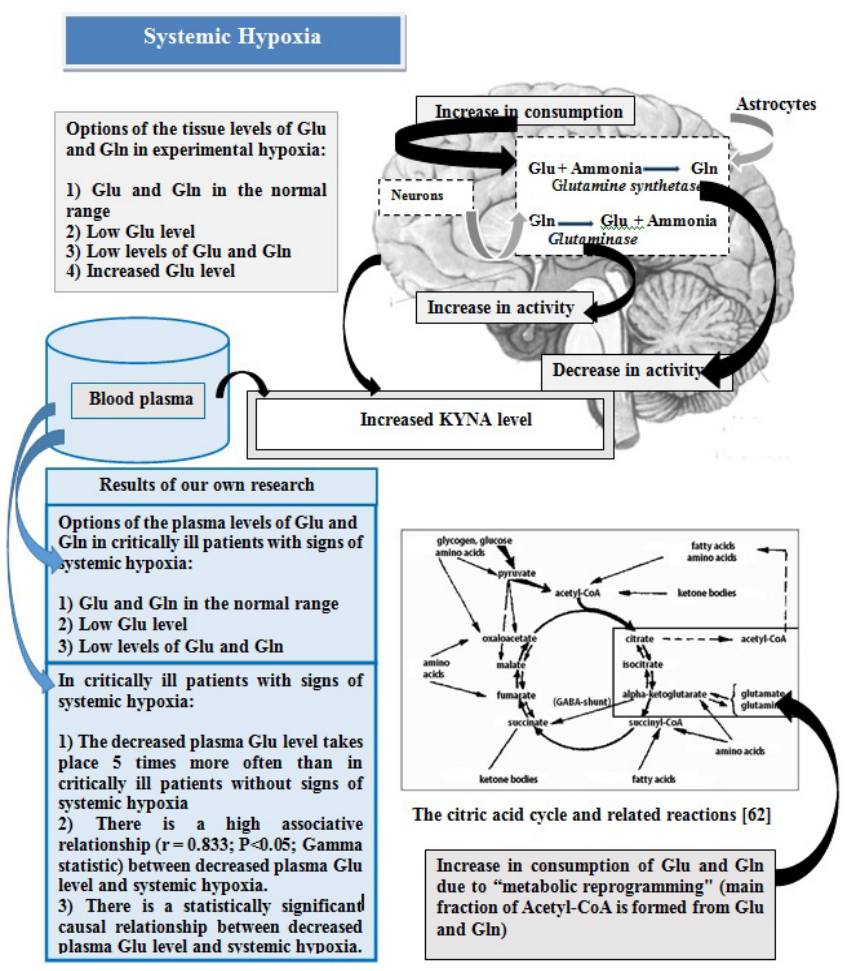

Fig. 2. Changes in the metabolism of Glu and Gln in hypoxic conditions

\section{RGN and acute kidney injury}

In a study conducted by $\mathrm{H}$. Chua et al., ${ }^{[64]}$ critically ill patients with acute kidney injury (AKI) in more than $50 \%$ of cases had plasma Glu levels below the reference value. In our early study, ${ }^{[65]}$ we found more frequent reduction in levels of Glu and Gln in the plasma of critically ill patients with AKI compared to critically ill patients without AKI. Frequency Glu reduction in plasma increased with the increasing severity of AKI: $50 \%$ for AKI-I and $73 \%$ for AKI-III ( $\mathrm{r}=0.481 ; \mathrm{P}=0.03)$. Relationships between the AKI development and reduced plasma Glu level, as well as with the degree of AKI severity, were shown in models of logistic regression and artificial neural networks. These data are consistent with the results of studies carried out on animals. In an experimental study performed by M. Duran et al., ${ }^{[66]}$ after the initiation of acute renal failure, which was modeled experimentally in two ways (ischemic and chemical forms), reduced Glu levels in the renal cortex and plasma were found in both cases. According to R. Goldstein et al., ${ }^{[67]}$ significantly decreased plasma Glu concentrations were found in cats with various stages of chronic renal failure. In experimental study of I. Montañés et al., ${ }^{[68]}$ the cortical concentrations of glutamine and glutamate in dogs were lower 
in the recovery phase (48 hours) after acute renal ischemia than in control kidneys. Changes in the metabolism of Glu, Gln and KYNA in the body during AKI, which were identified in the experimental and clinical studies, are shown in Figure 3.

KYNA is a known uremic toxin. ${ }^{[69]}$ Its content in patients with uremia exceeds the reference values by many times and correlates with the development of uremic symptoms. Toxic effects of the relevant concentrations of KYNA have been confirmed by experimental studies. ${ }^{[70]}$ In the study of D. Pawlak et al., ${ }^{[71]}$ in spite of haemodialysis, plasma KYNA concentration was elevated in uremic patients in comparison with healthy volunteers. The high concentrations of KYNA positively correlated with degree of the renal insufficiency in rats with experimental chronic renal failure. ${ }^{\text {[2] }}$

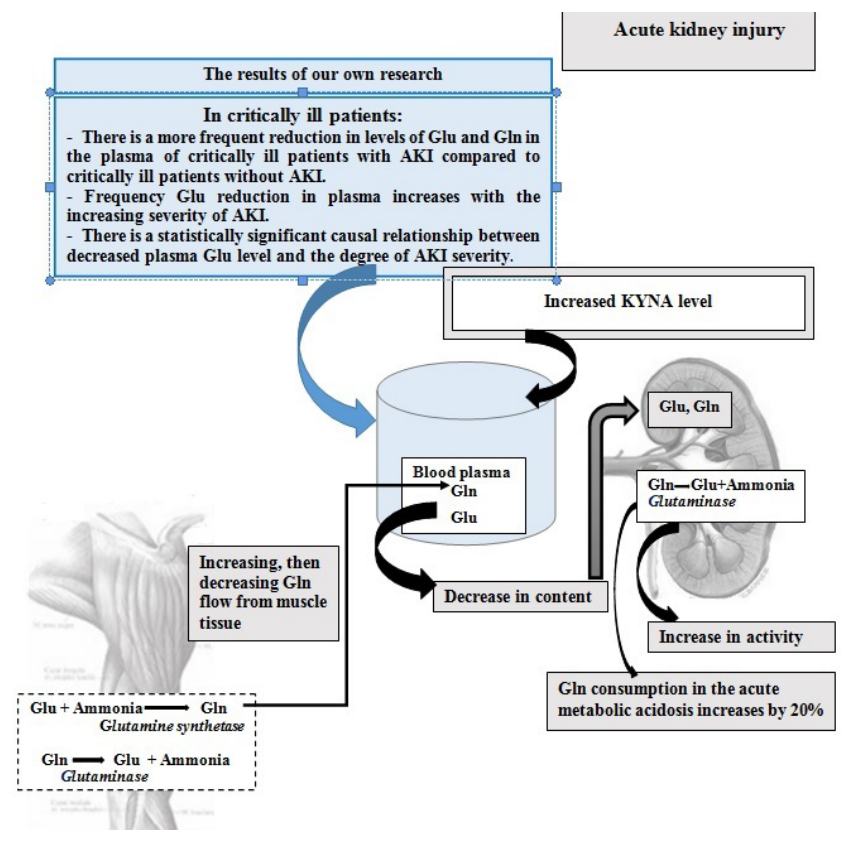

Fig. 3. Changes in the metabolism of Glu, Gln and KYNA in AKI

\section{RGN and sepsis}

Septic shock is a major cause of death in critically ill patients who are treated in ICUs. In patients with sepsis, according to R. Langley et al., ${ }^{[73]}$ the levels of Glu and Gln at enrollment to ICU and 24 hours later after treatment were significantly lower than in uninfected patients. Similar results were obtained in the study of W. Mickiewicz et al., ${ }^{[74]}$ thus, in the first 24 hours of admission to ICU, the plasma Glu concentration in patients with septic shock was lower than that of ICU patients with the systemic inflammatory response syndrome but not suspected of having an infection $(\mathrm{P}=0.00048)]$.

Our studies were carried out in 2013-2015 independently and simultaneously with foreign studies. In our studies and studies of foreign researchers, the "classical" diagnostic criteria for sepsis were applied (without revisions adopted in 2016). To enable comparison, all data are presented in the original version. According to our results, ${ }^{[75]}$ the decreased plasma Glu level was observed 9.8 times more frequently in ICU patients with sepsis compared to ICU patients without criteria for sepsis $(\mathrm{P}=0.00028$, ML chi-square test; $\mathrm{r}=0.890$, Gamma statistic ). With increasing severity of septic process (from severe sepsis to septic shock), frequency of the decreased plasma levels of Glu and Gln increased by 2 and 4 times, respectively $(\mathrm{P}=0.0208$, ML chi-square test; $\mathrm{r}=0.625, \mathrm{r}=0.730$, Gamma statistic). The causal link between the reduced Glu levels and the development of sepsis, as well as its severity, in ICU patients was shown in statistical models.

Clinical findings are consistent with experimental results. According to C. Boutry et al., ${ }^{[76]}$ with experimental endotoxemia almost all circulating AAs, including Glu, decreased. A supplementation with 4\% monosodium glutamate (MSG) or an isomolar amount of glutamine failed to restore Glu concentrations in plasma and muscle. A significant reduction in the concentration of extracellular Glu was determined during progressive inflammatory reaction induced by administration of LPS. ${ }^{[77]}$ E.V. Sabadash and S.N. Skornyakova, ${ }^{[78]}$ in a study on animals, showed a progressive decrease in the plasma Glu concentrations with an increase in the severity of infection.

H. Buter et al. ${ }^{[50]}$ described a correlation between preoperative plasma glutamine levels and the presence of a positive culture after cardiac surgery. In another study, ${ }^{[79]}$ researchers also found that plasma Glu levels were determined by the severity of illness and the presence of an infection in ICU patients.

A considerable amount of evidence has accumulated as concerns interactions between KP and immune dysregulation in the development of septic shock. KYNA is one of the end products of tryptophan formed in KP. In the first step of this process, tryptophan is oxygenized by TDO or IDO into kynurenine, which is then transformed by kynurenine aminotransferases into KYNA.

Physiological concentration of the human plasma KYNA ranges between $25 \mathrm{nM}$ and $60 \mathrm{nM} .^{[80,81]}$ IDO occupies a key position connecting the immune system and KP. ${ }^{[22,83]} \mathrm{As}$ is well known, IDO is rate-limiting enzyme of tryptophan catabolism and plays a pivotal role in immune tolerance.

P.Tattevin et al. ${ }^{[84]}$ showed that IDO activity gradually increased according to sepsis severity, and septic patients who died had higher IDO activity on admission than did survivors $(\mathrm{P}=0.013)$. IDO activity was markedly increased in patients with septic shock (0.235 [IQR, 0.152-0.481], +751\%, $\mathrm{P}<0.001)$, in patients with severe sepsis $(0.123$ [IQR, 0.068 $0.271],+344 \%, \mathrm{P}<0.001)$, and in patients with sepsis $(0.033$ [IQR, 0.031-0.052], $+20 \%, \mathrm{P}=0.008)$, as compared with control participants $(0.028$ [IQR, 0.025-0.036]). In addition, IDO activity was correlated with SAPS II score and day LOD score. As was shown, increasing plasma KYNA concentration might predispose to sepsis and septic shock in patients after multi trauma and its level is related to severity of infection. $[52,85,86]$

Changes in the metabolism of Glu, Gln and KYNA in the body during sepsis, which were identified in the experimental and clinical studies, are shown in Figure 4. 


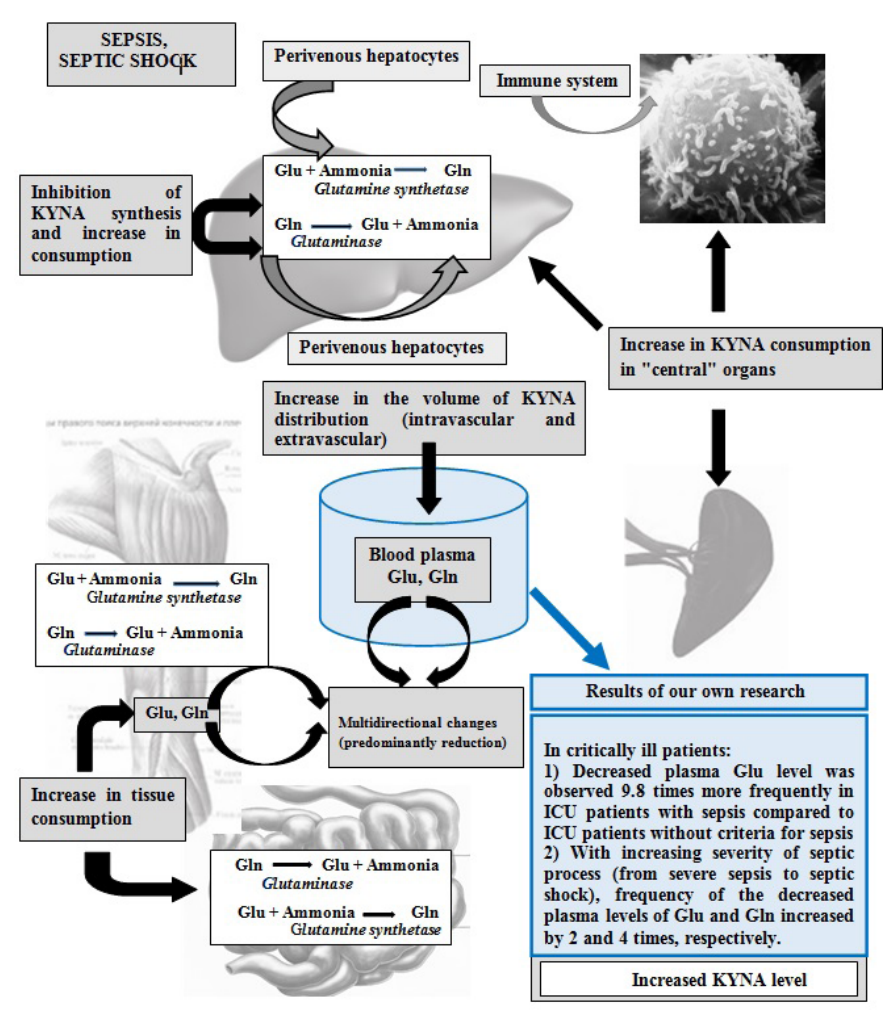

Fig. 4. Changes in the metabolism of Glu, Gln and KYNA in the body during sepsis.

\section{Factors of the "generalized" hypoaminoacidemia and increased KYNA content in the development of a patient's critical condition}

Factors of the "generalized" hypoaminoacidemia in the development of a patient's critical condition are the increased AA distribution due to vasodilation and increased permeability of the endothelium, an inhibition of the synthesis of a number of AAs in the liver and their increased consumption in central tissues (immune system, liver, spleen, wound). ${ }^{[46,87]}$

Experimental data have shown that stress factors increased the KYNA formation and other metabolites of KP of tryptophan catabolism by activating the secretion of glucocorticoids and a significant increase in the activity of $\mathrm{TDO}^{[88]}$ and IDO, which is regulated by cytokines. ${ }^{[89]}$ The increased KYNA concentration after acute physiological stress was observed in clinical studies performed by E. KotlinskaHasiec et al. ${ }^{[00]}$

\section{Conclusion}

There are many factors that can influence the course of the pathological process in critically ill patients. One of them, apparently, is RGN. In this review article, we have attempted to summarize the currently available evidence on the connection between low Glu content and a high KYNA level with each of the key mechanisms of thanatogenesis and unfavorable outcome in critically ill patients. The mechanisms behind the association of low plasma Gln levels and low Glu levels with severity of illness or mortality in critical illness are not fully understood. ${ }^{[91,92]}$ Whether plasma glutamine and glutamate levels can be used to identify critically ill patients with poor prognosis needs further study.

\section{Acknowledgments}

The author would like to express her deep appreciation and gratitude to her teacher, Professor Tamara S. Popova, Doctor of Biological Sciences, and all employees of the Central Clinical Hospital of the Presidential Administration of the Russian Federation for their comprehensive assistance.

\section{References}

1. Jobard E, Trédan O, Postoly D, André F, Martin AL, Elena-Herrmann B, et al. A Systematic Evaluation of Blood Serum and Plasma Pre-Analytics for Metabolomics Cohort Studies. Int J Mol Sci. 2016;17(12). pii: E2035.

2. Antcliffe D, Gordon AC. Metabonomics and intensive care. Crit Care. 2016; 20:68. doi: 10.1186/s13054-016-1222-8.

3. Beger RD, Dunn W, Schmidt MA, Gross SS, Kirwan JA, Cascante $\mathrm{M}$, et al. Metabolomics enables precision medicine: "A White Paper, Community Perspective". Metabolomics. 2016;12(10):149.

4. Mazzoli R, Pessione E. The Neuro-endocrinological Role of Microbial Glutamate and GABA Signaling. Front Microbiol. 2016;7:1934.

5. Hinoi E, Takarada T, Ueshima T, Tsuchihashi Y, Yoneda Y. Hinoi, E. Glutamate signaling in peripheral tissues. Eur J Biochem. 2004;271(1):1-13.

6. Perfilova VN, Tyurenkov IN. Glutamate lonotropic Receptors: Structure, Localisation, Function. Usp Fiziol Nauk. 2016;47(1):80-96. [Article in Russian].

7. Robinson MM, McBryant SJ, Tsukamoto T, Rojas C, Ferraris DV, Hamilton SK, et al. Novel mechanism of inhibition of rat kidney-type glutaminase by bis-2-(5-phenylacetamido1,2,4-thiadiazol-2-yl)ethyl sulfide (BPTES). Biochem J. 2007; 406(3):407-14.

8. Tremolizzo L, Sala G, Zoia CP, Ferrarese C. Assessing Glutamatergic Function and Dysfunction in Peripheral Tissues. Current Medicinal Chemistry. 2012; 19(9):1310-5. 9. Filpa V, Moro E, Protasoni M, Crema F, Frigo G, Giaroni C. Role of glutamatergic neurotransmission in the enteric nervous system and brain-gut axis in health and disease. Neuropharmacology. 2016;111:14-33. doi:10.1016/j. neuropharm.2016.08.024.

10. Abramov $\mathrm{Yu} \mathrm{B}$. Immune aspects of the central mechanisms of pain. Bol'. 2009; 4:2-8. [Article in Russian].

11. Davydova ON, Boldyrev AA. Glutamate receptors in cells of the nervous and immune systems. Annaly Klinicheskoy i Eksperimental'noy Nevrologii. 2007;4:28-34. [Article in Russian].

12. Stojic I, Srejovic I, Zivkovic V, Jeremic N, Djuric M, Stevanovic A, et al. The effects of verapamil and its combinations with glutamate and glycine on cardiodynamics, coronary flow and oxidative stress in isolated rat heart $\mathrm{J}$ Physiol Biochem. 2016; Nov 3. [Epub ahead of print]

13. Fujita S, Yokoyama U, Ishiwata R, Aoki R, Nagao K, Masukawa D, et al. Glutamate Promotes Contraction of the Rat Ductus Arteriosus. Circ J. 2016;80(11):2388-96.

14. Ishibashi-Shiraishi I, Shiraishi S, Fujita S, Ogawa S, Kaneko M, Suzuki M, et al. L-Arginine L-Glutamate Enhances 
Gastric Motor Function in Rats and Dogs and Improves Delayed Gastric Emptying in Dogs. J Pharmacol Exp Ther. 2016;359(2):238-46.

15. Descarries L, Bérubé-Carrière N, Riad M, Bo GD, Mendez JA, Trudeau LE. Glutamate in dopamine neurons: synaptic versus diffuse transmission. Brain Res Rev. 2008; 58(2):290-302.

16. Hnasko TS, Edwards RH. Neurotransmitter corelease: mechanism and physiological role. Annu Rev Physiol. 2012; 74:225-43. doi: 10.1146/annurev-physiol-020911-153315.

17. Uchida N. Bilingual neurons release glutamate and GABA. Nat Neurosci. 2014;17(11):1432-4. doi: 10.1038/ nn. 3840 .

18. Gomazkov OA. Neurogenesis as the adaptive function of the brain. Institute of Biomedical Chemistry named after V.N. Orekhovich: Moscow; 2014.

19. Brodsky VY, Malchenko LA, Konchenko DS, Zvezdina ND, Dubovaya TK. Glutamic Acid - Amino Acid, Neurotransmitter, and Drug - Is Responsible for Protein Synthesis Rhythm in Hepatocyte Populations in vitro and in vivo.Biochemistry (Mosc). 2016;81(8):892-8. doi: 10.1134 / S0006297916080101.

20. Du J, Li X.H, Li YJ. Glutamate in peripheral organs: biology and pharmacology. Eur J Pharmacol. 2016; 784:42-8. doi: 10.1016 / j.ejphar.2016.05.009.

21. Aleksandrova EV, Zaytsev OS, Potapov AA. Clinical syndromes of neurotransmitter system dysfunction in severe brain injury. Zhurnal nevrologii i psikhiatrii imeni S.S. Korsakova. 2015;115(7):40-6. [Article in Russian].

22. Dong XX, Wang Y, Qin ZH. Molecular mechanisms of excitotoxicity and their relevance to pathogenesis of neurodegenerative diseases. Acta Pharmacol Sin. 2009;30(4):379-87. doi:10.1038/aps.2009.

23. Lai TW, Zhang S, Wang YT. Excitotoxicity and stroke: identifying novel targets for neuroprotection. Prog Neurobiol. 2014;115:157-88. doi: 10.1016/j.pneurobio.2013.11.006.

24. Chen X, Wang K. The fate of medications evaluated for ischemic stroke pharmacotherapy over the period 1995-2015. Acta Pharm Sin B. 2016;6(6):522-30.

25. Castillo J, Loza MI, Mirelman D, Brea J, Blanco M, Sobrino T, et al. A novel mechanism of neuroprotection: Blood glutamate grabber. J Cereb Blood Flow Metab. 2016;36(2):292-301. doi: 10.1177/0271678X15606721.

26. Gan'shina TS, Kurza EV, Kurdyumov IN, Maslennikov DV, Mirzoyan RS. Peculiarities of the cerebrovascular effects of glutamic acid. Eksp Klin Farmakol. 2016;79(3):9-12.

27. Ryabov GA. Hypoxia in critical states. M.: Meditsina; 1988. 28. Timofeev IV. Illness and death. Selected lectures on clinical pathology and thanatology. St. Petersburg: DNA; 2016.

29. Wolahan SM, Hirt D, Glenn TC. Translational Metabolomics of Head Injury: Exploring Dysfunctional Cerebral Metabolism with Ex Vivo NMR SpectroscopyBased Metabolite Quantification. In: Kobeissy FH, editor. Brain Neurotrauma: Molecular, Neuropsychological, and Rehabilitation Aspects. Boca Raton (FL): CRC Press/Taylor \& Francis; 2015. Chapter 25.

30. Pozdeev VK. The neurochemical methods in clinical practice. St. Petersburg: Renome; 2013.

31. Brosnan JT. Interorgan amino acid transport and its regulation. J Nutr. 2003;133(6 Suppl 1):2068S-2072S.

32. Bein BN, Yezhova AA. Changes in the spectrum of free amino acids in the blood serum of patients with cerebrovascular disease. Vyatskii Med Vestnik. 2007;2-3:5-7. [Article in Russian].
33. Leibowitz A, Klin Y, Gruenbaum BF, Gruenbaum SE, Kuts R, Dubilet M, et al. Effects of strong physical exercise on blood glutamate and its metabolite 2-ketoglutarate levels in healthy volunteers. Acta Neurobiol Exp (Wars). 2012; 72(4):385-96.

34. Sem'yanov AV, Kazantsev VB. Neuron-glia interactions in the brain. Nizhny Novgorod; 2007.

35. Albuquerque EX, Schwarcz R. Kynurenic acid as an antagonist of $\alpha 7$ nicotinic acetylcholine receptors in the brain: facts and challenges. Biochem Pharmacol. 2013; 85(8):102732. doi: 10.1016/j.bcp.2012.12.014.

36. Tuboly G, Tar L, Bohar Z, Safrany-Fark A, Petrovszki Z, Kekesi G, et al. The inimitable Kinurenic acid: the roles of different ionotropic receptors in the action of Kinurenic acid at a spinal level. Brain Res Bull. 2015;112:52-60. doi: 10.1016/j. brainresbull.2015.02.001.

37. Wang Y, Moquin KF, Michael AC. Evidence for coupling between steady-state and dynamic extracellular dopamine concentrations in the rat striatum. J Neurochem. 2010;114(1):150-9. doi: 10.1111/j.1471-4159.2010.06740.

38. Passera E, Campanini B, Rossi F, Casazza V, Rizzi M, Pellicciari R, et al. Human Kinurenine aminotransferase II-reactivity with substrates and inhibitors. FEBS J. 2011; 278(11):1882-900. doi: 10.1111/j.1742-4658.2011.08106.

39. Borland LM, Michael AC. Voltammetric study of the control of striatal dopamine release by glutamat. J Neurochem. 2004;91(1):220-9.

40. Chen DY, Chen YM, Chien HJ, Lin CC, Hsieh CW, Chen $\mathrm{HH}$, et al. Metabolic Disturbances in Adult-Onset Still's Disease Evaluated Using Liquid Chromatography/Mass Spectrometry-Based Metabolomic Analysis. PLoS One. 2016; 11(12):e0168147. doi: 10.1371/journal.pone.0168147.

41. Theodoridis G, Gika HG, Wilson ID. LC-MS-based methodology for global metabolite profiling in metabonomics/ metabolomics. TRAC Trends Analytical Chem. 2008;27:251260.

42. Dias DA, Jones OA, Beale DJ, Boughton BA, Benheim D, Kouremenos KA, et al. Current and Future Perspectives on the Structural Identification of Small Molecules in Biological Systems. Metabolites. 2016;6(4). pii: E46.

43. Godlewska BR, Pike A, Sharpley AL, Ayton A, Park $\mathrm{RJ}$, Cowen PJ, et al. Brain glutamate in anorexia nervosa: a magnetic resonance spectroscopy case control study at 7 Tesla. Psychopharmacology (Berl). 2017;234(3):421-26. doi: 10.1007/s00213-016-4477-5.

44. Kwon YK, Ha IJ, Bae HW, Jang WG, Yun HJ, Kim $\mathrm{SR}$, et al. Dose-dependent metabolic alterations in human cells exposed to gamma irradiation. PLoS One. 2014;9(11)e113573. doi: 10.1371/journal.pone.0113573.

45. Korochanskaya SP, Storozhuk PG, Bykov IM. Educational and methodical manual on biological chemistry. Krasnodar; 2016. [in Russian].

46. Poeze M, Luiking YC, Breedveld P, Manders S, Deutz NE. Decreased plasma glutamate in early phases of septic shock with acute liver dysfunction is an independent predictor of survival. Clin Nutr. 2008;27(4):523-30. doi: 10.1016/j. clnu.2008.04.006.

47. Hirose T, Shimizu K, Ogura H, Tasaki O, Hamasaki T, Yamano S. et al. Altered balance of the aminogram in patients with sepsis - The relation to mortality. Clin Nutr. 2014; 33(1):179-82. doi: 10.1016/j.clnu.2013.11.017.

48. Alekseeva EV, Popova TS, Sal'nikov PS. Low levels of glutamine, glutamic acid and citrulline in plasma as risk factors 
for the 28-day survival in critically ill patients. Patogenez. 2016;14 (2):48-57. [Article in Russian].

49. Alekseeva EV. Possibility of correction of hypofunction of glutamatergic neurotransmitter system in critically ill patients. Kremlin medicine. Clin Vestnik. 2016;4:137-51. [Article in Russian].

50. Buter H, Koopmans M, Kemperman R, Jekel L, Boerma C. Plasma glutamine levels before cardiac surgery are related to post-surgery infections; an observational study. J Cardiothorac Surg. 2016;11(1):155.

51. Lin YR, Li CJ, Syu SH, Wen CH, Buddhakosai W, Wu HP, et al. Early Administration of Glutamine Protects Cardiomyocytes from Post-Cardiac Arrest Acidosis. Biomed Res Int. 2016;2016:2106342. doi: 10,1155 / 2016/2106342.

52. Dabrowski W, Kocki T, Pilat J, Parada-Turska J, Malbrain ML. Changes in plasma kynurenic acid concentration in septic shock patients undergoing continuous veno-venous haemofiltration. Inflammation. 2014;37(1):223-34. doi: 10.1007/s10753-013-9733-9.

53. Ristagno G, Latini R, Vaahersalo J, Masson S, Kurola $\mathrm{J}$, Varpula $\mathrm{T}$, et al. Early activation of the kynurenine pathway predicts early death and long-term outcome in patients resuscitated from out-of-hospital cardiac arrest. J Am Heart Assoc. 2014;3(4). pii: e001094. doi: 10.1161/ JAHA.114.001094.

54. Darlington LG, Mackay GM, Forrest CM, Stoy N, George $\mathrm{C}$, Stone TW. Altered kynurenine metabolism correlates with infarct volume in stroke. Eur J Neurosci. 2007;26(8):2211-21. 55. Alekseeva EV. Changes in plasma content of glutamic acid in critically ill patients during hypoxia. Journal of Modern Clinical Medicine. 2016;9(5):14-25. [Article in Russian].

56. Brose SA, Marquardt AL, Golovko MY. Fatty acid biosynthesis from glutamate and glutamine is specifically induced in neuronal cells under hypoxia J Neurochem. 2014; 129 (3):400-12. doi: 10.1111/jnc.12617.

57. Fan J, Kamphorst JJ, Rabinowitz JD, Shlomi T. Fatty acid labeling from glutamine in hypoxia can be explained by isotope exchange without net reductive isocitrate dehydrogenase (IDH) flux. J Biol Chem. 2013;288(43):31363-9. doi: 10.1074/jbc.M113.502740.

58. Fan J, Kamphorst JJ, Mathew R, Chung MK, White E, Shlomi T. Glutamine-driven oxidative phosphorylation is a major ATP source in transformed mammalian cells in both normoxia and hypoxia. Mol Syst Biol. 2013;9:712. doi: 10.1038/msb.2013.65.

59. Metallo CM, Gameiro PA, Bell EL, Mattaini KR, Yang J, Hiller K, et al. Reductive glutamine metabolism by IDH1 mediates lipogenesis under hypoxia. Nature. 2011;481 (7381):380-4. doi: 10.1038/nature10602.

60. Wise DR, Ward PS, Shay JE, Cross JR, Gruber JJ, Sachdeva $\mathrm{UM}$, et al. Hypoxia promotes isocitrate dehydrogenasedependent carboxylation of $\alpha$-ketoglutarate to citrate to support cell growth and viability. 2011;108(49): 19611-6. doi: 10.1073/pnas.1117773108.

61. Baran H, Kepplinger B, Herrera-Marschitz M, Stolze K, Lubec G, Nohl H. Increased kynurenic acid in the brain after neonatal asphyxia. Life Sci. 2001;69(11):1249-56.

62. Ashmarin IP, Stukalov VP. Neurochemistry. Institute of Biomedical Chemistry of the RAMS: Moscow; 1996.

63. Ceresoli-Borroni G, Schwarcz R. Neonatal asphyxia in rats: acute effects on cerebral kynurenine metabolism. Pediatr. Res. 2001;50:231-35.

64. Chua HR, Baldwin I, Fealy N, Naka T, Bellomo R.
Amino acid balance with extended daily diafiltration in acute kidney injury. Blood Purif. 2012;33(4):292-9. doi: $10.1159 / 000335607$.

65. Alekseeva EV, Sal'nikov PS. Changes in the levels of glutamic acid and glutamate in the blood plasma of the critically ill patients with impaired liver and kidney function. Pathogenez. 2016;14(1):72-83. [Article in Russian].

66. Duran MA, Spencer D, Weise M, Kronfol NO, Spencer RF, Oken DE. Renal epithelial amino acid concentrations in mercury-induced and postischemic acute renal failure. Toxicol Appl Pharmacol. 1990;105(2):183-94.

67. Goldstein RE, Marks SL, Cowgill LD, Kass PH, Rogers QR. Plasma amino acid profiles in cats with naturally acquired chronic renal failure. Am J Vet Res. 1999;60(1):109-13.

68. Montañés I, Badía A, Réngel MA, López-Novoa J M. Renal cortical intermediary metabolism in the recovery phase of postischemic acute renal failure in the dog. Proc Soc Exp Biol Med. 1992;199(3):321-6.

69. Sallée M, Dou L, Cerini C, Poitevin S, Brunet P, Burtey $\mathrm{S}$. The aryl hydrocarbon receptor-activating effect of uremic toxins from tryptophan metabolism: a new concept to understand cardiovascular complications of chronic kidney disease. Toxins (Basel). 2014;6(3):934-49. doi:10.3390/ toxins6030934.

70. Terent'yev AA, Kazimirsky AN, Efremov AD. Biological oxidation and bio-energy. N.I. Pirogov RNRMU Moscow; 2012.

71. Pawlak D, Pawlak K, Malyszko J, Mysliwiec M, Buczko W. Accumulation of toxic products degradation of kynurenine in hemodialyzed patients. Int Urol Nephrol. 2001;33(2):399-404.

72. Pawlak D, Tankiewicz A, Buczko W. Kynurenine and its metabolites in the rat with experimental renal insufficiency. J Physiol Pharmacol. 2001;52(4 Pt 2):755-66.

73. Langley RJ, Tsalik EL, van Velkinburgh JC, Glickman SW, Rice BJ, Wang C, et al. An integrated clinico-metabolomic model improves prediction of death in sepsis. Sci Transl Med. 2013;5(195):195ra95. doi: 10.1126/scitranslmed.3005893.

74. Mickiewicz B, Tam P, Jenne CN, Leger C, Wong J, Winston BW. Alberta Sepsis Network. Integration of metabolic and inflammatory mediator profiles as a potential prognostic approach for septic shock in the intensive care unit. Crit Care. 2015;19:11. doi: 10.1186/s13054-014-0729-0.

75. Alekseeva EV. Selected aspects of the necessity in the correction of the decreased glutamic acid content in patients with severe sepsis and septic shock. Vestnik Sovremennoi Klinicheskoi Medicinye. 2016;6:169-78. [Article in Russian]. 76. Boutry C, Matsumoto H, Bos C, Moinard C, Cynober L, Yin Y. Decreased glutamate, glutamine and citrulline concentrations in plasma and muscle in endotoxemia cannot be reversed by glutamate or glutamine supplementation: a primary intestinal defect ? Amino Acids. 2012;43(4):1485-98.

77. Noworyta-Sokołowska K, Górska A, Gołembiowska K. LPS-induced oxidative stress and inflammatory reaction in the rat striatum. Pharmacol Rep. 2013;65(4):863-9.

78. Sabadash EV, Skornyakov SN. The method for assessing the severity of TB infection. RF Patent № 2305286. UNIIF State Agency for Health Care; appl. 22.08.2005; publ. 27.08.2007.

79. Buter H, Bakker AJ, Kingma WP, Koopmans M, Boerma EC. Plasma glutamine levels in patients after non-elective or elective ICU admission: an observational study. BMC Anesthesiol. 2016;16:15. doi: 10.1186/s12871-016-0180-7.

80. Kotlinska-Hasiec E, Nowicka-Stazka P, Parada-Turska J, Stazka K, Stazka J, Zadora P, et al. Plasma kynurenic acid 
concentration in patients undergoing cardiac surgery: effect of anaesthesia. Arch Immunol Ther Exp (Warsz). 2015;63(2): 129-37. doi: 10.1007/s00005-014-0312-z.

81. Turski MP, Turska M, Paluszkiewicz P, Parada-Turska J, Oxenkrug GF. Kynurenic acid in the digestive system: new facts, new challenges. Int J Tryptophan Res. 2013;6:47-55

82. Mándi Y, Vécsei L. The Kinurenine system and immunoregulation. J Neural. Transm. 2012;119(2):197-209. doi: 10.1007/s00702-011-0681-y.

83. Schmidt SV, Schultze JL. New Insights into IDO Biology in Bacterial and Viral Infections. Front Immunol. 2014;5:384. doi: 10.3389/fimmu.2014.00384.

84. Tattevin P, Monnier D, Tribut O, Dulong J, Bescher N, Mourcin F, et al. Enhanced indoleamine 2,3-dioxygenase activity in patients with severe sepsis and septic shock. J Infect Dis. 2010; 201(6):956-66. doi: 10.1086/650996.

85. Schefold JC, Zeden JP, Fotopoulou C, von Haehling $\mathrm{S}$, Pschowski R, Hasper $\mathrm{D}$, et al. Increased indoleamine 2,3-dioxygenase (IDO) activity and elevated serum levels of tryptophan catabolites in patients with chronic kidney disease: a possible link between chronic inflammation and uraemic symptoms. Nephrol Dial Transplant. 2009;24(8):1901-8. doi: 10.1093/ndt/gfn739.

86. Zeden JP, Fusch G, Holtfreter B, Schefold JC, Reinke P, Domanska G, et al. Excessive tryptophan catabolism along the kynurenine pathway precedes ongoing sepsis in critically ill patients. Anaesth Intensive Care. 2010;38(2):307-16.

87. Soeters PB, Grecu I. Have we enough glutamine and how does it work? A clinician's view. Ann. Nutr. Metab. 2012;60 (1):17-26. doi: 10.1159/000334880.

88. Shilov YE, Bezrukov MV. Kynurenines in pathogenesis of endogenous psychiatric disorders. Annals of the Russian academy of medical sciences. 2013;68(1):35-41. doi:10.15690/ vramn.v68i1.535 [Article in Russian].

89. Chiappelli J, Pocivavsek A, Nugent KL, Notarangelo FM, Kochunov P, Rowland LM, et al. Stress-induced increase in Kinurenic acid as a potential biomarker for patients with schizophrenia and distress intolerance. JAMA Psychiatry. 2014; 71(7):761-8. doi: 10.1001/jamapsychiatry.2014.243.

90. Kotlinska-Hasiec E, Nowicka-Stazka P, Parada-Turska J, Stazka K, Stazka J, Zadora P, et al. Plasma Kinurenic acid concentration in patients undergoing cardiac surgery: effect of anaesthesia. Arch Immunol Ther Exp (Warsz). 2015; 63(2):129-37. doi: 10.1007/s00005-014-0312-z.

91. Wernerman J. How to understand the results of studies of glutamine supplementation. Crit Care. 2015;19:385. doi: 10.1186/s13054-015-1090-7.

92. Wernerman J. What Is Actually Attributable to Glutamine? JPEN J Parenter Enteral Nutr. 2017;41(1):9. doi: 10,1177 / 0148607116637938. 